\title{
Assessment of ultrastructure in isolated cochlear hair cells using a procedure for rapid freezing before freeze- fracture and deep-etching
}

\author{
A. FORGE ${ }^{1 *}$, S. DAVIES ${ }^{1}$ and G. ZAJIC ${ }^{2}$ \\ ${ }^{1}$ Structural Biology Laboratory, and Department of Audiology, Institute of Laryngology and Otology, University College London, \\ 330-332 Gray's Inn Road, London WC1X 8EE, UK \\ ${ }^{2}$ Kresge Hearing Research Institute, University of Michigan, Ann Arbor, Michigan, USA
}

Received 14 June 1990; revised 5 September and 12 November 1990; accepted 23 November 1990

\begin{abstract}
Summary
Separated cochlear outer hair cells and isolated strips of organ of Corti containing hair cells and supporting cells have been capidly frozen before freeze-fracture and deep-etching by immersion of samples sandwiched between two copper plates into liquid nitrogen-cooled propane:isopentane. Assessment of this procedure has shown that no significant freezing damage occurs. The ultrastructure of the hair cells revealed by freeze-fracture of these non-chemically fixed preparations was generally very similar to that seen in fixed material. This indicates that the processing of cochlear tissue normally used for electron microscopy produces few obvious structural artefacts. It also demonstrated that procedures for isolating cochlear hair cells generally do not affect cell structure significantly. However, some isolated hair cells did show abnormalities within the membranes of the lateral cisternae. Such membrane alterations, which would not be identified by light microscopy, occurred to a variable extent but were more commonly present after prolonged periods in maintenance medium. Deep-etching of the preparations to examine extracellular features around stereocilia revealed clearly lateral cross-links between stereocilia. However, tip-links could not be positively identified in either unfixed or prefixed preparations.
\end{abstract}

\section{Introduction}

The development over the past few years of procedures for rapidly freezing tissue without the formation of damaging ice crystals (Menco, 1986 for review) has allowed studies of unfixed tissue and the dynamic processes occurring in cells (Heuser et al., 1979). Such procedures are potentially of importance in contemporary studies of the sensory 'hair' cells of the mammalian organ of Corti, the neuroepithelium of the cochlea.

Hair cells, which are involved in the transduction of mechanical stimuli to neural output, derive their name from the presence at their apical ends of an organized bundle of erect stereocilia (hairs). These are rigid and are composed of actin filaments (Flock \& Cheung, 1977). In the organ of Corti two types of hair cell are recognized. The inner hair cells are directly innervated exclusively by afferent nerves and are considered to be mechanically passive receptor cells. The outer hair cells receive an extensive direct afferent innervation. It has been postulated that in vivo outer hair cells actively

* To whom correspondence should be addressed. modulate cochlear micromechanics to effect a fine tuning of the incoming acoustic signals before detection by the inner hair cells-(Kemp, 1978). Recently methods have been developed for isolating cochlear outer hair cells and maintaining them in short-term culture (Brownell et al., 1984), and it has been demonstrated that the isolated cells have motile properties. Under a number of conditions they may shorten relatively slowly (Zenner et al., 1985; Dulon et al., 1987, $1988,1990)$ in a manner reminiscent of muscular contraction (Flock et al., 1986) but they are also capable of rapid cycles of reversible contraction at auditory frequencies (Ashmore, 1987). These observations have stimulated a great deal of interest in determining the activities of outer hair cells. However, these studies have been carried out using light microscopy and there have been few attempts to assess the ultrastructure in isolated hair cells to discover whether the isolation and incubation procedures have adverse effects on the highly specialized cell structure. In part 
this is the result of difficulties in processing the preparations for electron microscopy as only a few hundred, delicate outer hair cells can be isolated in a reasonable time (Zajic \& Schacht, 1987; Holley, 1988). Potentially rapid-freezing followed by freeze-fracture would be an ideal method to study the ultrastructure in such preparations as there is a minimum of processing and therefore of cell loss. In addition, possible artefacts induced by chemical fixation would be avoided. It has been suggested (Evans, 1990) that fixation of cells in situ causes rearrangement of the lateral cisternae, a prominent organized, endoplasmic reticulum-like membrane system parallel to the lateral plasma membrane, which is a unique structural specialization of outer hair cells.

An additional advantage of rapid freezing procedures is that they also enable the use of deep-etching after freeze-fracture to examine extracellular surface details at high resolution (Heuser \& Salpeter, 1979). This is of significance in the present context because it has been suggested that extracellular fine cross-links at the tips of stereocilia may be intimately involved with the control of transduction channel opening (Pickles et al., 1984; Hudspeth, 1989). There is no direct evidence for this but in any assessment of possible adverse effects of isolation procedures on the ultrastructure of outer hair cells it is important to discover whether tip-links are present in isolated hair cells. Furthermore, we have previously shown by freezefracture that there are particular specializations of the membrane at the tip of the stereocilia which could be the sites of the transduction channels (Forge et al., 1988). Deep-etching would provide one means of examining tip-links at high resolution and determining their relationship to the stereociliary membrane.

In previous studies of inner ear tissues, impact freezing has been used to rapidly freeze-fix the neuroepithelium of the vestibular system (balance organ) of chicks (Hirokawa \& Tilney, 1982) and guinea pigs (Arima et al., 1987) as well as the organ of Corti (Arima et al., 1986) but in this last work only supporting cells were readily visualized. There appear to be no studies in which hair cells from the mammalian cochlear have been examined after rapid freezing. The initial aim of the present work then was to develop a method which could be used easily and routinely for rapidly freezing cochlear hair cells. Impact freezing requires the subsequent use of cleavage with a knife to obtain fracture and this is difficult to perform with the very small samples to be used. We therefore decided to investigate the use of samples sandwiched between two copper plates and then immersed in liquid propane, as described by Costello and co-workers (1984). This technique has been shown to produce very high cooling rates with no detectable ice crystal formation (Costello et al., 1984) and following freezing, fracture is easily achieved by separating the sandwich. Consequently the method has been particularly recommended for small samples and cell suspensions (Costello et al., 1982). In this paper we show that this method routinely enables rapid freezing of isolated strips of the organ of Corti and as well as fully separated hair cells without detectable damage from ice crystal growth. Using this technique in conjunction with freeze-fracture and deep-etching we have assessed the ultrastructure in these preparations of isolated hair cells.

\section{Materials and methods}

Cochleae were obtained from adult, pigmented guinea pigs, $250-400 \mathrm{~g}$ in weight and free from ear infection. The animals were decapitated and the auditory bullae removed and widely opened to expose the cochlea. The bony wall of the cochlea was also opened before the bulla was transferred to Hanks Balanced Salt Solution (HBSS), pH 7.3, osmolarity adjusted to $300 \mathrm{mOsm}$, at $20^{\circ} \mathrm{C}$. This medium was used throughout; the osmolarity is approximately that of cochlear perilymph and has been shown to be optimal for the maintenance of the gross morphology of outer hair cells (Zajic \& Schacht, 1987).

\section{Preparation of strips of organ of Corti}

The bullae were immersed in HBSS, the bone picked off the cochlea, and strips of organ of Corti were gently teased away from the basilar membrane with a fine wire probe. Material from two to four cochleae was collected and pooled in a $20 \mu \mathrm{l}$ droplet of medium. Some preparations were frozen directly ('unfixed' samples) either immediately after isolation of the strips, approximately 30-35 $\mathrm{min}$ after death of the animal, or after incubation in medium for a further $30-45 \mathrm{~min}$. This was

Fig. 1. Thin-section of outer hair cell. The cell is cylindrical in shape with multiple membranes, the lateral cisternae, parallel to the lateral plasma membrane. Mitchondria are associated with the inner aspect of the cisternae. The cuticular plate appears as an amorphous region at the cell apex from which the stereocilia arise. $\times 2000$. Scale bar: $5.0 \mu \mathrm{m}$.

Fig. 2. Thin section of inner hair cell. The cell is flask shaped and bent at the neck. The cuticular plate and stereocilia are present at the cell apex. $\times 4000$. Scale bar: $2.5 \mu \mathrm{m}$.

Fig. 3. Freeze-fracture of fresh-frozen isolated outer hair cell. Lateral cisternae appear as continuous, concentric fenestrated sheets in face view (lc) and as continuous, parallel membranes in cross-fracture (arrow). Mitochondria can be seen adjacent to the inner aspect of the cisternae and at the base of the cell beneath the nucleus. $\times 5000$. Scale bar: $2.5 \mu \mathrm{m}$.

Fig. 4. Freeze-fracture of fresh-frozen strip of organ of Corti. The apices of three outer hair cells are identified by the images of the cross-fractured stereocilia organized in a characteristic W-form on each cell. The apices of the supporting cells which surround each hair cell are bulging outwards and possess few microvilli. $\times 4800$. Scale bar: $2.5 \mu \mathrm{m}$. 

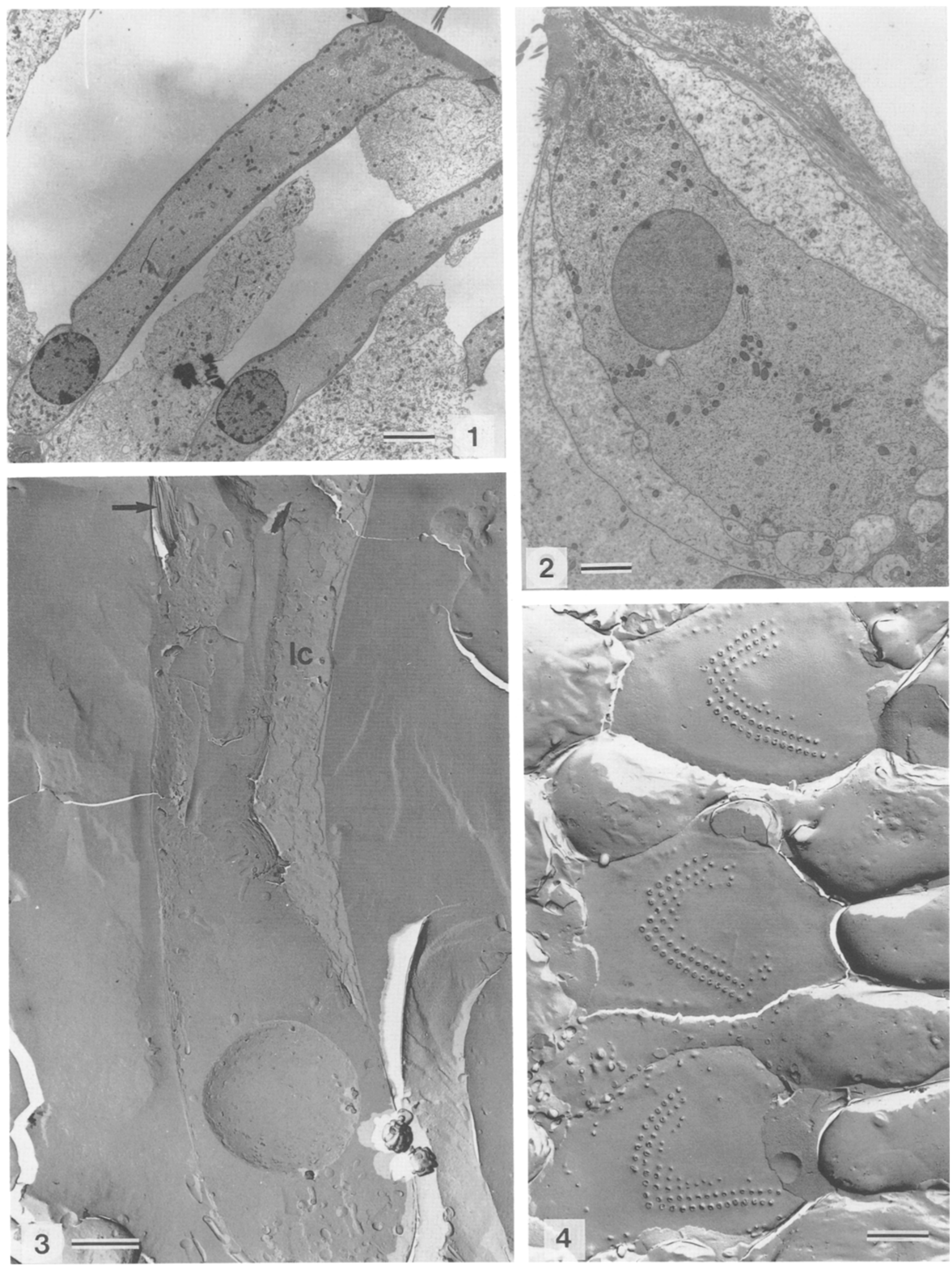
to examine the effects of prolonged periods of ex corporeal maintenance. In other preparations, after isolation (approximately $30 \mathrm{~min}$ post mortem), the strips were briefly fixed for 5-10 min by adding to the droplet containing the tissue an equal volume of $2.5 \%$ glutaraldehyde in either HBSS or cacodylate buffer (i.e. final fixation in $1.25 \%$ glutaraldehyde). The fixed samples were briefly rinsed in distilled water or $15 \%$ aqueous methanol (Hirokawa \& Tilney, 1982) before immediate freezing.

\section{Isolation of hair cells}

Outer hair cells were isolated from the apex of the cochlea by the technique of Zajic and Schacht (1987). The apical two turns of the cochlea were removed from the cochlea and. incubated for $10 \mathrm{~min}$ at room temperature (approximately $20^{\circ} \mathrm{C}$ ) in $1 \mathrm{mg} \mathrm{ml}^{-1}$ collagenase (Type IV, from Clostridium histolyticum; Sigma) in HBSS, then placed in fresh HBSS. The hair cells were dissociated manually from the basilar membrane and collected into a small drop (approximately $10 \mu \mathrm{l}$ ) of fresh HBSS. These were directly frozen either immediately (30-45 min post mortem) or after $30-45 \mathrm{~min}$ incubation in medium.

\section{Mounting samples}

Copper, 'hat type' freeze-fracture planchettes, $0.1 \mathrm{~mm}$ thick with a raised, flat platform $2.5 \times 3.0 \mathrm{~mm}$ (Balzers High Vacuum Limited, Berkhamsted, UK) were treated before use with concentrated nitric acid (Costello et al., 1982). This was necessary to ensure adhesion of the sample to the specimen supports. The planchettes were covered with water and about twice the volume of concentrated nitric acid added. As soon as the evolution of brown nitrogen dioxide began, the acid was rapidly diluted with a large excess of distilled water, and the planchettes washed three times with water, then three times in acetone and dried in air. This whole procedure was then repeated. After evaporation of the acetone by air drying, the planchettes were stored in an oven at $60^{\circ} \mathrm{C}$ until used.

Mounting of samples was carried out in a petri dish containing a piece of tissue paper soaked in medium; this provided a humid atmosphere to prevent drying of the small sample volumes and maintain the osmolarity of the medium. Strips of organ of Corti were taken up with approximately $5 \mu \mathrm{l}$ of the attendant fluid ( $300 \mathrm{mOsm}$ HBSS for unfixed samples, water or $15 \%$ aqueous methanol in samples which had been pre-fixed (see earlier)), deposited on one planchette and allowed to stand for a few seconds before a second planchette was placed on top and gently pushed down on to the sample to spread the fluid. The sandwich was then inverted and left for a few seconds before freezing. For the isolated hair cells, approximately $2-3 \mu$ l of cell suspension was sandwiched between two copper planchettes following the same procedure.

\section{Rapid freezing}

Freezing was accomplished in a rapidly stirred mixture of $4: 1$ propane:isopentane contained in a brass tube with a thick copper base and cooled in a liquid nitrogen bath. The sample was propelled into the cryogen by gravity using the device designed for impact freezing by Phillips and Boyne (1984), but modified to enable immersion freezing by using the jaws of an appropriately positioned spanner to halt the fall of the freezing head. A sandwiched sample was picked up with cross-over forceps by one wing of one planchette and the forceps mounted in the freezing device. The sample descended approximately $10 \mathrm{~cm}$ before entering the propane-isopentane and then travelled through approximately $3 \mathrm{~cm}$ of the rapidly stirred cryogen before the descent was halted. The frozen samples were transferred to liquid nitrogen for storage.

\section{Freeze-fracture and deep-etching}

The sandwiched samples were mounted in a Balzers double replica device of the type which clamps the wings of the planchettes (BB $172221 \mathrm{~T}$ ). Fracture was performed in a Balzers BAF $400 \mathrm{D}$ apparatus at a pressure of $2-4 \times 10^{-7}$ mBar. For freeze-fracture only, fracture was performed at $-115^{\circ} \mathrm{C}$ and the surfaces shadowed with platinum from $45^{\circ}$ and carbon from $90^{\circ}$. For deep-etching, fracture was carried out at a registered stage temperature of either $-90^{\circ}$ or $-95^{\circ} \mathrm{C}$. As suggested by Haggis (1985), fracture was performed 20-30 min after the desired temperature was first

Fig. 5. Freeze-fracture replica showing stereocilia in which distortions of the membrane from the formation of large ice crystals are present. $\times 48000$. Scale bar: $0.25 \mu \mathrm{m}$.

Fig. 6. Freeze-fracture of stereocilia in well-frozen, unfixed sample. The membranes of stereocilia have a smooth contour with dispersed IMP and there is no evidence of ice crystal-induced deformations. $\times 48000$. Scale bar: $0.25 \mu \mathrm{m}$.

Fig. 7. Freeze-fracture. P-fracture face of apical membrane of outer hair cell in rapidly-frozen, unfixed preparation. There is no obvious distortion of the membrane and IMP are evenly spaced. There is little detail clearly resolved in the cross-fractures of the stererocilia in these unetched preparations. $\times 45000$. Scale bar: $0.25 \mu \mathrm{m}$.

Fig. 8. Freeze-fracture. E-fracture face of the apical membrane of outer hair cell in the replica complementary to that shown in Fig. 7. Large IMP are dispersed over the fracture face. Such E-face IMP are not seen in fixed, cryoprotected material. $\times 45000$. Scale bar: $0.25 \mu \mathrm{m}$.

Fig. 9. Freeze-fracture. Lateral cisternal membrane of outer hair cell in unfixed, rapidly frozen preparation. pm, plasma membrane. The lateral cisternae appear as fenestrated membrane sheets with IMP evenly dispersed over the fracture face. Again the membrane contour shows no evidence of distortion from ice-crystal formation. $\times 30000$. Scale bar: $0.25 \mu \mathrm{m}$.

Fig. 10. Complementary freeze-fracture replicas of lateral cisternal membranes in unfixed, rapidly frozen preparation. Some of the IMP appear as fibrils (arrow), but there are no impressions corresponding to these on the opposite face. $\times 40000$. Scale bar: $0.25 \mu \mathrm{m}$. 

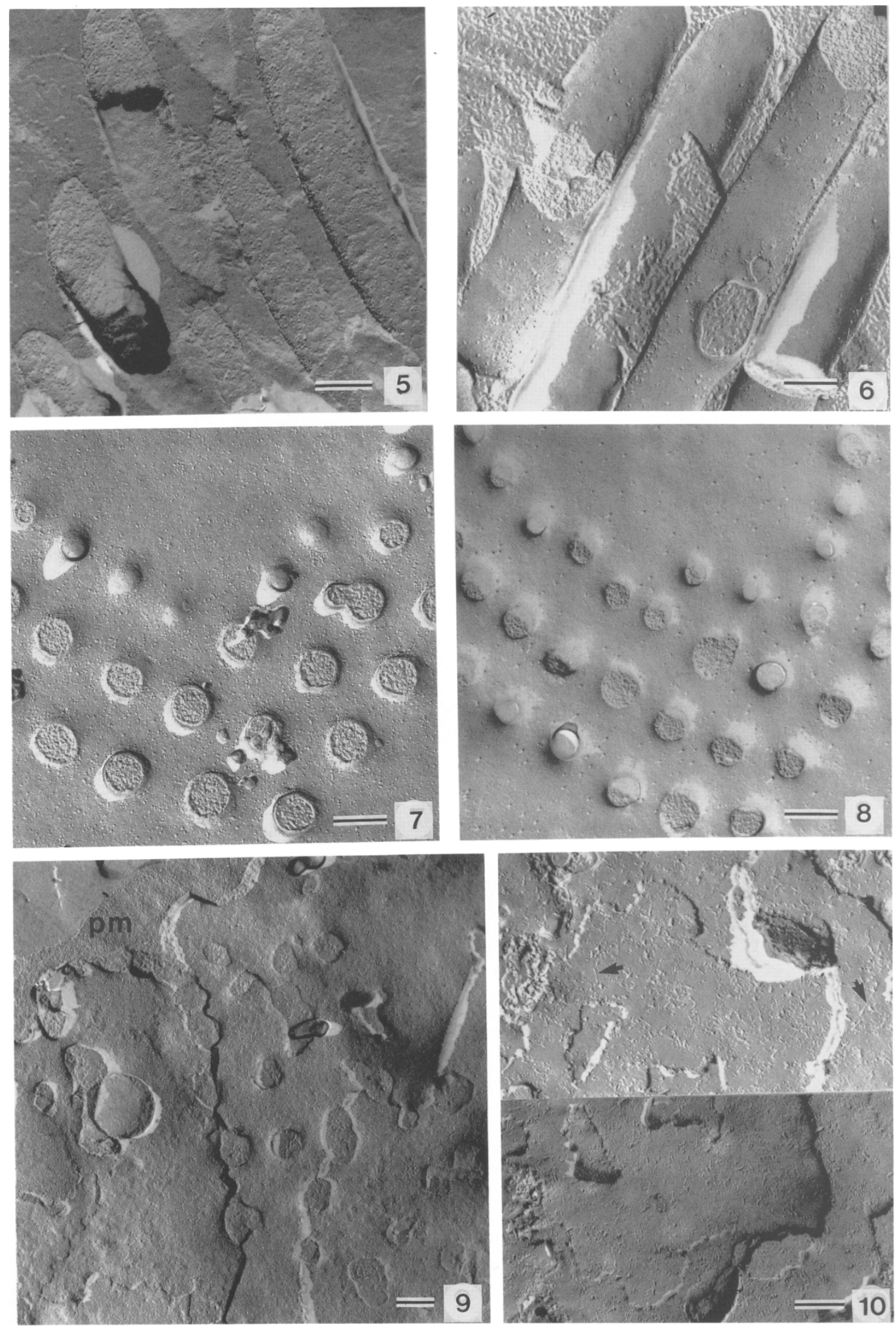
registered. The fracture surfaces were etched for $10 \mathrm{~min}$. Platinum was deposited from $22^{\circ} \mathrm{C}$ while the sample was rotating at approximately 60 r.p.m. Carbon was deposited from $90^{\circ}$.

Following replication the samples were removed from the apparatus and each planchette carefully floated on to the surface of chromic acid (Fetter \& Costello, 1986). As soon as the copper had dissolved leaving the intact replica floating, the replica was transferred using a thin glass rod on to $30 \%$ chrome-sulphuric acid. It was left to clean for $2 \mathrm{~h}$ to overnight before washing by transfer through four baths of distilled water.

In presenting the results, rotary shadowed samples have been printed in reverse contrast, and stereopairs have been mounted for viewing with a magnifying pocket steroviewer.

\section{Results}

To aid in understanding the results from the rapid freezing study, thin sections showing what is considered to be the characteristic morphology of the hair cells are shown in Figs 1 and 2 and some salient features are described (for a fuller description see Davies \& Forge, 1987). The outer hair cell (Fig. 1) is cylindrical. At its apical end is an amorphous-appearing structure, the cuticular plate, from which the stereocilia arise. Along the lateral wall of the outer hair cell is a series of parallel membranes, the lateral cisternae, with which mitochondria are associated on the inner aspect. At the base of the cell are synapses with efferent and afferent nerve endings. The hair cell body is surrounded by fluid spaces but at the apical end, the outer hair cells are separated from each other by the heads of adjacent supporting cells. The inner hair cell (Fig. 2) is flask-shaped and the structures at the apical end are similar to those in the outer hair ceil. There is, however, a much less extensive lateral cisternal system. Each inner hair cell is completely surrounded by adjacent supporting cells.

\section{Assessment of the preparative procedure}

It was possible to obtain fracture both of isolated hair cells (Fig. 3) and of strips of organ of Corti (Fig. 4). The strips of organ of Corti consisted of outer hair cells held together by adjacent supporting cells and often contained inner hair cells as well. Because fracture occurred along the length of the strip, several hair cells could be examined in one sample.

Freeze-fracture replicas of preparations frozen immediately after isolation were examined to determine whether detectable ice crystal formation had disrupted structure. Distortions of the membrane fracture faces, similar to those described as resulting from ice crystal damage (Gilkey \& Staehelin, 1986), were easily recognized (Fig. 5) but occurred extensively in only one preparation out of more than 40 examined. In the majority of freeze-fracture preparations, as judged by morphological criteria, good freezing was apparent throughout the length of hair cells. The membranes of the stereocilia (Fig. 6) and of the apical plasma membrane of the cell (Figs 7 and 8) were smooth, as were the membranes of the lateral cisternae in the lateral wall of the outer hair cells (Figs 9 and 10). On the lateral membrane of the inner hair cell, the regular particle arrays previously described in fixed and glycerinated tissue (Forge, 1987) were clearly resolved and uninterrupted (Fig. 11). At the base of the outer hair cell, nuclear membranes showed no obvious ice crystal damage (Fig. 12) and within efferent nerve endings synaptic vesicles were not distorted and were closely packed (Fig. 13), indicating that large ice crystals had not formed in the cell cytoplasm.

To assess possible peculiarities related exclusively to the use of unfixed tissue or any particular artefacts associated with fracturing such material, the membrane fracture faces were examined in detail to compare with the features seen in previous studies of fixed, glycerinated tissue (Forge 1986, 1987, 1989; Forge et al., 1988). The P-faces of the stereocilia (Fig. 6) and the apical membrane (Fig. 7) showed relatively few dispersed intramembrane particles (IMP) whereas IMP were densely packed on the lateral plasma membrane (Fig. 9) as previously reported for pre-fixed material (Forge, 1986, 1989; Forge et al., 1988). However, the E-face of the apical membrane (Fig. 8) showed a small number of large IMP, which appeared similar to some of the particles on the P-face and are not seen in fixed, glycerinated preparations. This anomaly probably results from the effects of fixation on particle partitioning during fracture (Newman \& Duce, 1986). A further anomaly was observed on the membranes of the lateral cisternae. In addition to the dispersed IMP (Fig. 9) present in prefixed material (Forge, 1986) these fracture faces also showed short fibrils (Fig. 10). However, the use of complementary replicas (Fig. 10) showed that the presence of a fibril on one face did not correspond to a groove on the equivalent opposite face, indicating that the fibrils resulted from deformation of some IMPs as a consequence of a lack of stabilization in the absence of fixation.

The procedures used also enabled deep-etching to be successfully accomplished. This too confirmed the absence of significant freezing damage. Inside the hair cells a clear distinction of the cuticular plate from the rest of the cell cytoplasm in both inner and outer hair cells was evident (Figs 14 and 15). The cuticular plate appeared as a dense meshwork of fibrils and there were no discontinuities within it as might be expected if ice crystals had formed. The characteristic form of the cuticular plate observed in thin sections was also clearly seen (Fig. 14) and within the rest of the cytoplasm cell organelles were recognizable. The fact that following fixation and washing in aqueous 

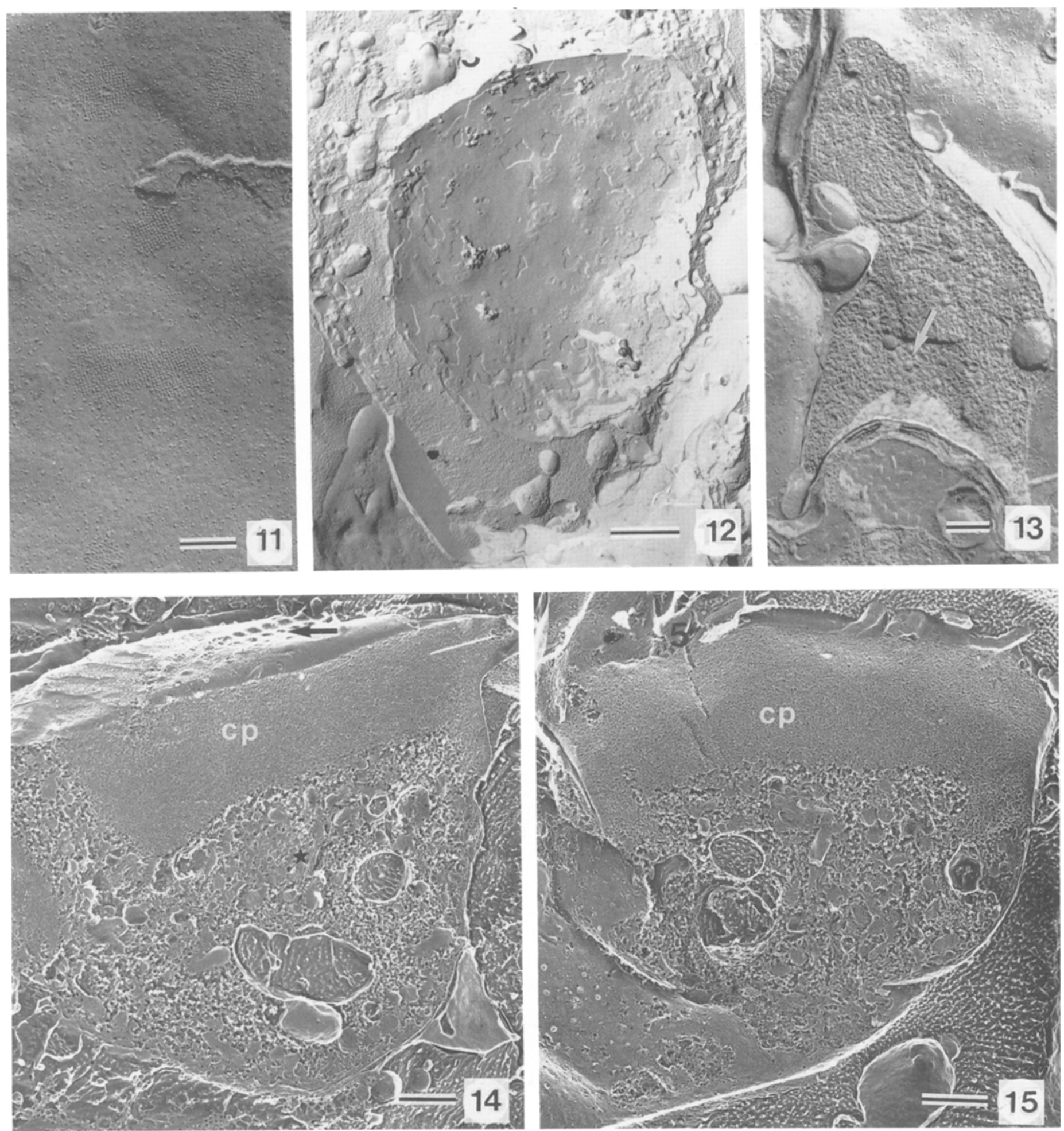

Fig. 11. Inner hair cell lateral plasma membrane in unfixed, rapidly-frozen preparation. There is no obvious distortion of the membrane. Regions of the membrane where particles are organized in regular square arrays are clearly resolved. $\times 40000$. Scale bar: $0.25 \mu \mathrm{m}$.

Fig. 12. The nucleus of an outer hair cell in an unfixed, rapidly frozen preparation shows no distortion from ice crystal formation. $\times 12000$. Scale bar: $1 \mu \mathrm{m}$.

Fig. 13. Cross-fractured efferent nerve terminal at the base of an outer hair cell in a rapidly-frozen, unfixed preparation. Slight etching has occurred to reveal the synaptic vesicles (arrow) which are distinct and closely packed indicating that no large ice crystals have developed. $\times 30000$. Scale bar: $0.25 \mu \mathrm{m}$.

Fig. 14. Deep-etch, rotary-shadowed replica of fixed outer hair cell in a strip of organ of Corti. The cuticular plate (cp) at the apex of the cell is clearly differentiated and appears as a meshwork of filaments. Its characteristic shape is revealed: on the side of the cell towards the centre of the cochlear spiral (at the right) the cuticular plate has a basalward extension, while on the opposite side (towards the outside of the cochlea) there is a region from which the cuticular plate is absent. Arrow indicates cross-fractured stereocilia on the apical membrane of the cell. Organelles, including a meshwork of endoplasmic reticulum (*), are dispersed in the cytoplasm with mitochondria associated with the lateral wall of the cell. $\times 10000$. Scale bar: $1 \mu \mathrm{m}$.

Fig. 15. Deep-etched inner hair cell. The characteristic bend at the neck of the cell is apparent. Again, the cuticular plate (cp) is clearly distinguished. $\times 12000$. Scale bar: $1 \mu \mathrm{m}$. 
methanol the outer hair cells showed an approximately circular cross-sectional profile (Fig. 14) and inner hair cells (Fig. 15) the characteristic 'bent neck' morphology (Fig. 2) also indicated that these pretreatments did not induce gross morphological disturbances. The advantages of using these pretreatment procedures before deep-etching was seen in examining stereocilia. In fixed washed preparations (Fig. 20) the surfaces of the stereocilia were clearly exposed, but in unfixed samples frozen directly in HBSS (Fig. 22) irregular deposits covered the surfaces. These presumably were the solutes in the medium remaining after the sublimation of the water (Miller et al., 1983).

\section{Assessment of cell structure}

Having established that the freezing procedure did not induce structural artefacts and after identifying the peculiarities associated with the preparation procedures, it was possible to assess ultrastructure in the hair cells. The general morphology of most hair cells in the isolated preparations appeared very similar to that of fixed hair cells in the intact organ of Corti (Fig. 1). The isolated hair cells were cylindrical in shape (Figs 3 and 19) and the apical surface was flat with no blebbing (Fig. 4). The lateral cisternae were present in several closely concentric layers running parallel to the lateral plasma membrane (Fig. 3) and did not seem to be unduly enlarged in comparison with thin sections of cells fixed in situ (Fig. 1). The cisternae appeared as continuous membrane sheets interrupted by irregular fenestrations (Figs 3 and 9). The nucleus was spherical and in its expected location towards the base of the outer hair cell (Fig. 3). Mitochondria were localized on the inner aspect of the cisternae, below the nucleus (Fig. 3), and in the region just below the cuticular plate (Figs 14 and 15).

However, although most cells showed a general morphology consistent with that seen in thin sections, very occasionally there were cells which had retained a cylindrical shape but in which the lateral cisternae appeared to be disorganized and vesiculated (Fig. 16). Such gross disruption was rarely observed but detailed studies revealed more subtle abnormalities of the lateral cisternal membranes in a larger number of cells which appeared otherwise to be normal. Three kinds of peculiarity were recognised: distinct bare areas of membrane devoid of IMP (Fig. 17); smooth surfaced (i.e. particle-free) invaginations (Fig. 19); and extended sheets of particle-free membrane within the plane of the cisterna in which there were no fenestrations, but yet which were continuous with normal appearing fenestrated cisternal membrane (Fig. 18). These abnormalities were found to a varying extent in all preparations but usually affected only a small minority of the cells frozen as soon as possible after isolation. In preparations incubated for longer periods a greater number of cells appeared to show these anomalies; in some (but not all) preparations frozen after the longest time in maintenance medium (approximately, $1.5 \mathrm{~h}$ ), nearly all cells showed at least the presence of bare patches on the cisternal membrane.

The deep-etching of the isolated hair cell preparations clearly revealed the presence of fibrillar lateral cross-links between the stereocilia (Fig. 20). The fibrils, approximately $3 \mathrm{~nm}$ in diameter, were present between stereocilia along a row and between rows and in some cases the fibrils between adjacent stereocilia could be seen to interdigitate to form a central density in the space midway between the two stereocilia. A similar organization has been observed in thin sections of cells fixed in situ (Davies \& Forge, 1987). However, besides the lateral cross-links, the actual surface of the stereociliary shaft did not show the fairly extensive fibrillar coat exposed on the surfaces of the stereocilia in vestibular hair cells from chicks (Hirokawa \& Tilney, 1982). Furthermore, there was no structure consistently revealed at the apical end of the stereocilium in either fixed (Fig. 21) or unfixed material (Fig. 22) which could be unequivocally identified as corresponding to the tip-link observed in scanning electron microscopy and thin sections of fixed, intact organ of Corti (Pickles et al., 1984; Furness \& Hackney, 1985). One example of connections at the tip of a stereocilium to the longer one adjacent was observed (arrow, Fig. 21) but this did not show the single fibril

Fig. 16. Isolated outer hair cell in preparation frozen after a total time of approximately $90 \mathrm{~min}$ in HBSS. The lateral cisternae are unrecognizable and the cell is full of vesicles but the cylindrical shape is retained. $\times 6000$. Scale bar: $2.0 \mu \mathrm{m}$.

Fig. 17. Lateral cisternal membrane in unfixed preparation showing distinct, localised IMP-free areas of the fracture face. $\times 40000$. Scale bar: $0.25 \mu \mathrm{m}$.

Fig. 18. Freeze-fracture replica of lateral cisternae in unfixed preparation showing extensive smooth faced, i.e. IMP-and fenestra-free, area within the plane of the cisternal membrane. This appears to be continuous with normal appearing cisternal membrane (black arrow) and is blebbing inwards $\left(^{*}\right)$ indicating incipient vesiculation. Open arrow denotes multiple lipid lamellae associated with the membrane. $\times 16000$. Scale bar: $0.5 \mu \mathrm{m}$.

Fig. 19. Stereopair of deep-etch replica of unfixed hair cells showing smooth-surfaced invagination of the cisternal membrane. The cylindrical shape of the cell is clear and the fenestrations within the cisternal membrane can be identified. $\times 20000$. Scale bar: $0.5 \mu \mathrm{m}$. 

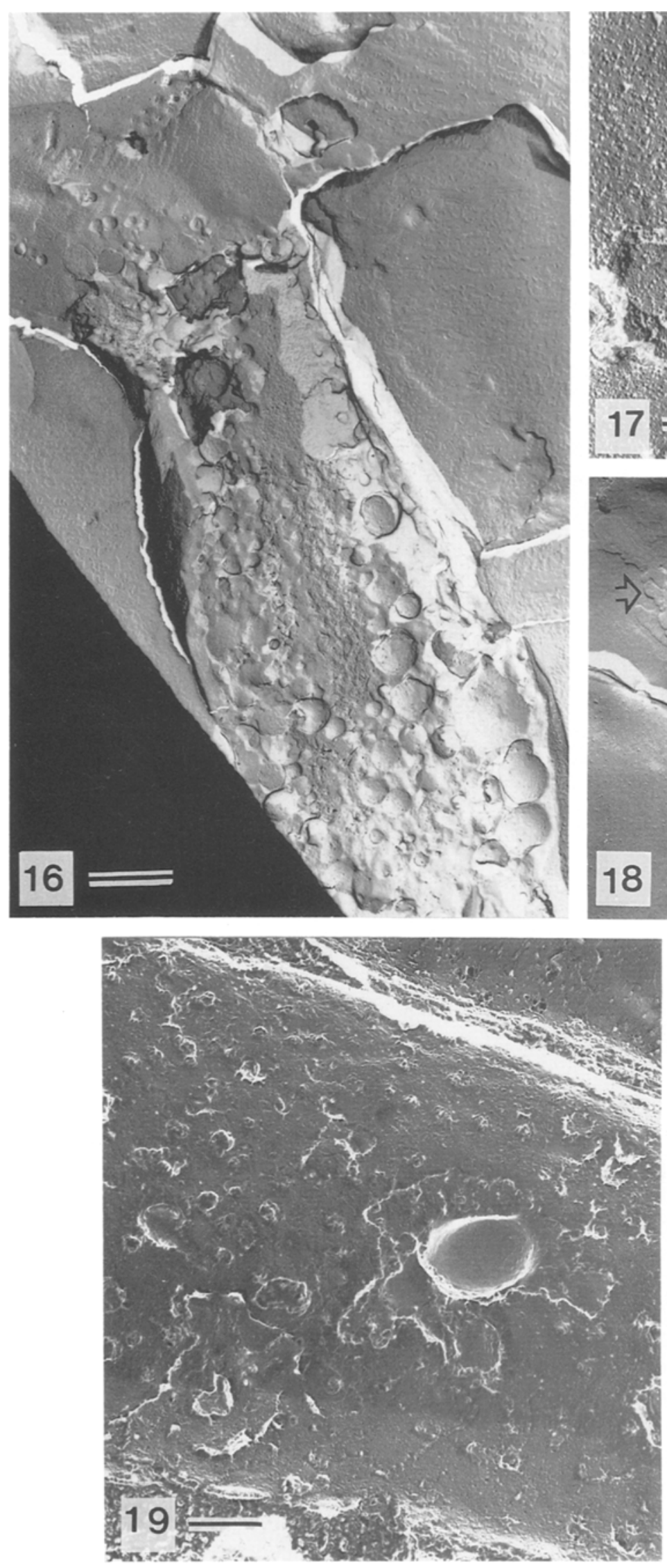
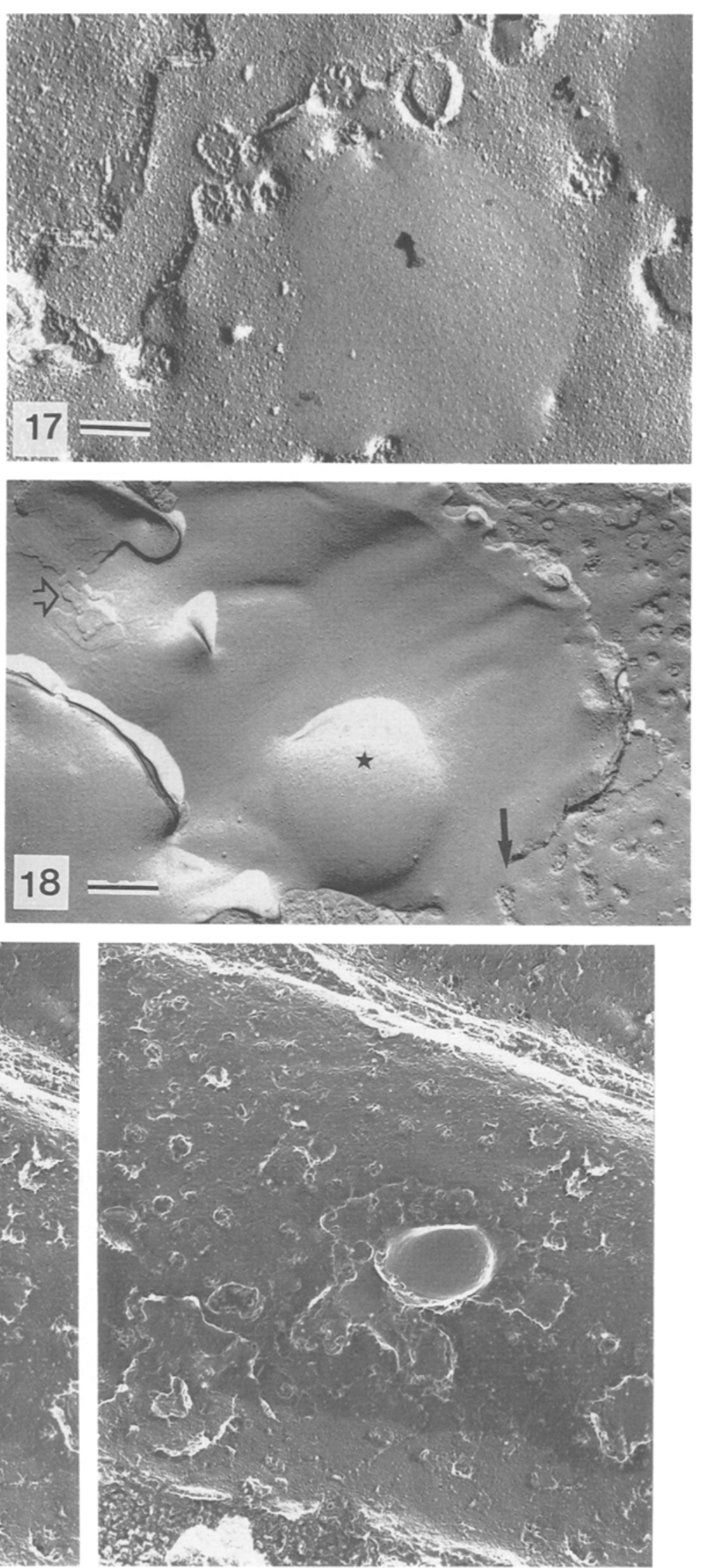
form associated with stereociliary tip-links and no cross-linking was apparent at the apical ends of other stereocilia.

The inability to identify extracellular material other than the lateral cross-links on the surface of the stereociliary shaft was not the result of removal of material during fixation and washing before freezing. In deep-etched, unfixed specimens frozen directly (Fig. 22), despite the presence of irregular deposits of salts from the maintenance medium, lateral crosslinks could be identified (arrow, Fig. 22) but the actual surfaces of the stereocilia revealed by etching were as smooth as they were in prefixed, washed samples (Figs 20 and 21).

\section{Discussion}

This study is the first in which cochlear hair cells have been examined after using rapid freezing procedures. The results clearly show that the technique described here facilitated sufficiently fast freezing to prevent the development of damaging ice crystals throughout the length of hair cells. As the method is also easy to apply, detailed studies of ultrastructural correlates of dynamic events in hair cells are now possible either via freeze-fracture and deep-etching or by using thin sections after freeze-substitution. Such studies are being initiated in this laboratory.

The samples used for this investigation, separated outer hair cells and strips of organ of Corti, both represent preparations of hair cells isolated from the cochlea and maintained in culture medium. Isolation procedures may expose the cells to potentially damaging conditions such as hypoxia and the non-physiological environment of the culture medium. However, none of the structural abnormalities of outer hair cells reported to result from such adverse conditions (Shirane \& Harrison, 1987; Billet et al., 1989), such as swelling of the cell body, cisternal distension, localized blebbing of the hair cell apex behind the stereociliary bundle, or fusion of stereocilia, was observed. Indeed, the fine details of cell architecture and of cell membrane structure in the unfixed cells were no different from those seen in conventional freeze- fracture preparations or thin sections of the intact organ of Corti. This suggests that standard fixation and tissue processing procedures produce no significant structural artefacts. The present findings also imply that isolation procedures, including the use of collagenase in separating individual hair cells from supporting cells, may not in general have adverse effects on hair cell structure. However, abnormalities of the lateral cisternae were noted and stereociliary tip-links could not be identified, and the possible significance of these anomalies needs to be considered.

The lateral cisternae in cells frozen immediately after isolation appeared predominantly as fenestrated sheets, the morphology observed in conventional freeze-fracture preparations (Forge, 1986) and deduced from the discontinuity of the cisternal membranes in thin sections. This confirms that this thin section appearance is probably not an artefact arising from the sensitivity of the cisternae to the conditions imposed during preparation of tissue for electron microscopy. This conflicts with recent thin section observations of fixed, isolated hair cells reported by Evans (1990) which suggest that cisternae are normally formed of continuous, uninterrupted membranes. The cells examined by Evans were predominantly from the apical end of the cochlea. Studies in this laboratory (Forge, unpublished) have shown that the extent of cisternal fenestration within outer hair cells varies with location along the cochlear spiral with the membranes of cells at the apical end possessing very few fenestrations. This could account for the apparent discrepancy between the two studies.

However, as Evans (1990) also suggests, cisternal membrane structure does appear to be highly vulnerable. Changes to cisternal membrane structure which could ultimately result in extensive vesiculation and disorganization of the cisternae were identified. Most commonly, after prolonged periods in culture medium, bare (particle-free) patches developed. It appeared that this could lead to either localized invaginations or to enlargement into extensive sheets of particle-free membrane with concomitant formation of vesicles. Such alterations would not be identifiable

Fig. 20. Stereopair of outer hair cell stereocilia in a fixed and washed preparation. Lateral cross-links are present between stereocilia along a row and between rows. The cross-links from adjacent stererocilia appear to overlap in the middle of the gap between the stereocilia to form a central density. The surfaces of the stereocilia exposed by the etching are smooth where no cross-links are present. $\times 48000$. Scale bar: $0.25 \mu \mathrm{m}$.

Fig. 21. Tips of stereocilia exposed in a deep-etch preparation of fixed, washed material. Lateral cross-links are resolved. Arrow indicates connections between one stereocilium and a longer one adjacent. However, tip-links are not apparent elsewhere. Some stereocilia are broken. $\times 48000$. Scale bar: $0.25 \mu \mathrm{m}$.

Fig. 22. Stereocilia in a fresh-frozen, deep-etch preparation. Arrows indicate lateral cross-links but these are not as well defined as in the fixed preparation shown in Fig. 21 because the salts from the tissue culture medium in which the cells were frozen remain after etching, obscuring details and forming deposits on the exposed surfaces. Nevertheless, it can be seen that the surfaces of the stereocilia exposed by etching are smooth. $\times 48000$. Scale bar: $0.25 \mu \mathrm{m}$. 

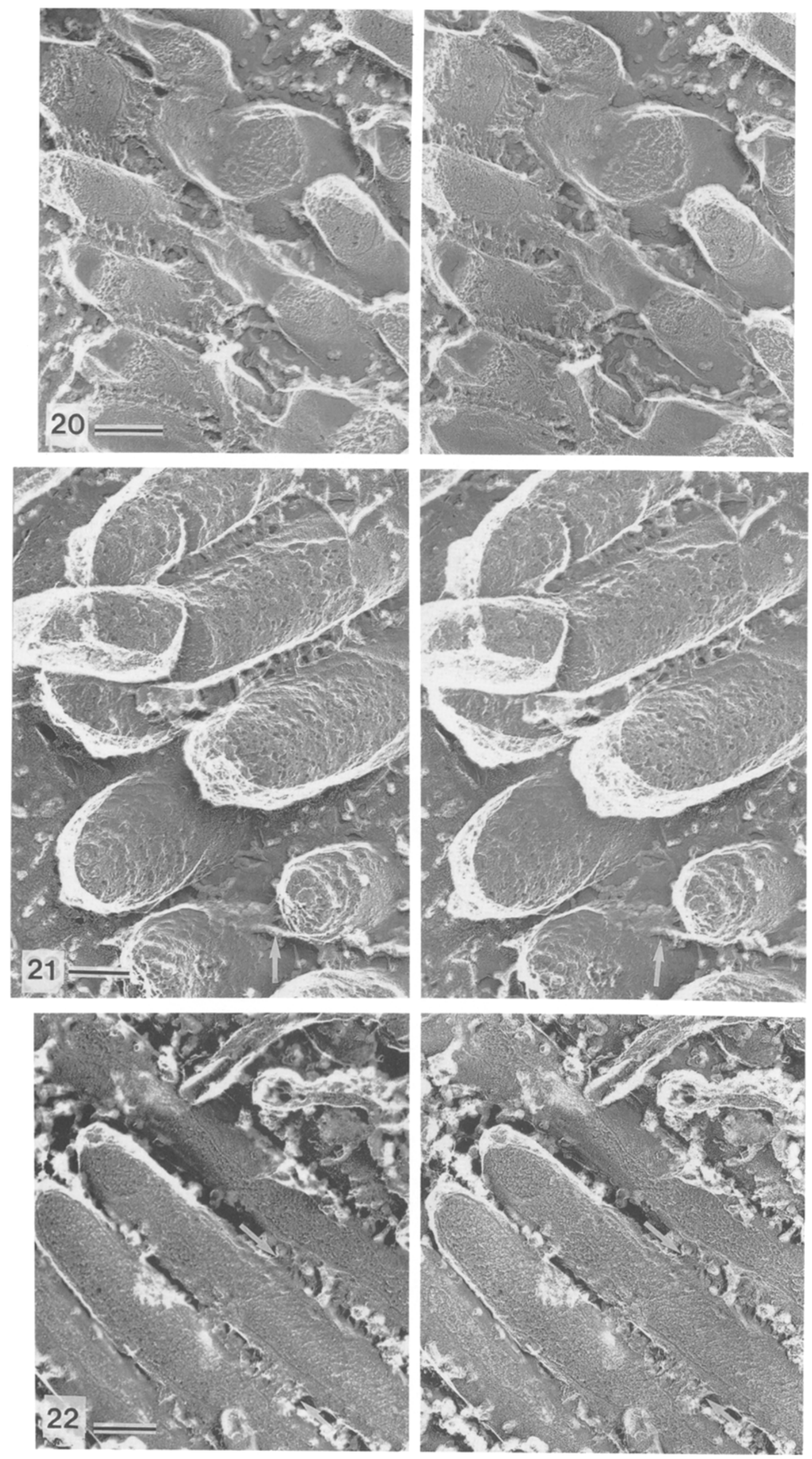
by light microscopy. Smooth IMP- and fenestra-free areas of the cisternal membrane have also been noted in the earliest stages of damage to hair cells caused by aminoglycoside antibiotics (McDowell et al., 1989). Taken with the present observations this suggests that cisternal membranes may be susceptible to adverse conditions. Thus, alterations to cisternal membrane structure might be a sensitive indicator of hair cell condition. It is also noteworthy that even when the cisternae were disorganized the cells retained a cylindrical morphology. This may imply that the cisternae do not contribute directly to the maintenance of cell shape.

The development of bare patches on membranes is thought to result from changes in the phase of some membrane lipids leading to localized separation of lipid and protein (IMP) components (Pinto da Silva, 1972). One common cause of such phase separation is cooling of the membrane below the lipid phase transition temperature and membranes with a low cholesterol content, which therefore are relatively fluid, are particularly susceptible to such phase separation (De Leeuw et al., 1990). Studies of the responses of cochlear hair cells to filipin (Forge, in preparation), a probe for membrane cholesterol (Severs \& Robenek, 1983), indicate that the cisternal membranes contain little cholesterol. Therefore the appearance of bare areas in the cisternal membranes of these unfixed hair cells may be a consequence of phase separation induced by low temperature. It seems unlikely that this is an artefact of the freezing process since there were no other indications of freezing-induced damage and there is no evidence that phase separation leads to membrane vesiculation within the short time scales involved in the tissue freezing process. Also, the incidence of bare patches on cisternal membranes appeared to be related to the length of time the cells were in culture medium. All procedures between the death of the animal and freezing of the tissue were carried out at room temperature. It is possible therefore that it is the maintenance of cells below body temperature that induces phase separation. It would be of interest to discover whether incubation of cells at a higher temperature prevents the development of cisternal alterations.

The absence of stereociliary tip-links in the preparations examined in the present study could be due to mechanical rupture of the thin $(6 \mathrm{~nm})$ fibrils during dissection and mounting of the specimen or because of exposure of the cells to non-physiological conditions. There is evidence that extracellular material at the apices of cochlear hair cells can be easily removed (Santi \& Anderson, 1987). In particular it has been claimed that tip-links are especially vulnerable to tissue handling and processing procedures (Pickles et al., 1984). In some preparations in the present study stereociliary bundles did appear to be disorganized and some stereocilia showed breaks (illustrated in Fig. 21) suggesting mechanical disturbances. The separation of the organ of Corti from the basilar membrane with a minimum of mechanical stress is now being attempted in further efforts to discover whether tip-links can be identified in preparations of isolated outer hair cells. It is also possible that the conditions imposed on the cells by isolation and/or the use of HBSS, which is composed predominantly of $\mathrm{NaCl}$, adversely affects the tip-links; in vivo the apices of the hair cells and the stereocilia are bathed in a potassiumrich fluid (endolymph). However, tip-links have been identified by thin sectioning and scanning electron microscopy when sodium-rich buffers are used throughout tissue processing (Pickles et al., 1984; Furness \& Hackney, 1985; Forge et al., 1988). Furthermore, the hair cells in explants of mouse organ of Corti grown in culture in HBSS show responses to mechanical stimulation similar to those of cells in vivo (Russell et al., 1986) suggesting they are able to transduce, and what appear to be tip-links can be recognized in the cultured hair cells (Furness et al., 1989). On the other hand, a fibrillar coat, not seen in the present work, was observed on the surfaces of the stereocilia of chick vestibular hair cells when potassium-rich buffers were used (Hirokawa \& Tilney, 1982). It has also been suggested recently that links between stereocilia undergo rapid post-mortem disruption (Osborne \& Comis, 1990). It should be noted, however, that lateral cross-links between stereocilia were clearly resolved in the present work. Thus, whatever the reasons for the absence of tip-links, lateral cross-links between stereocilia would seem to be less susceptible to damage than other fibrillar components of the stereociliary surface coat, if such other components do indeed exist on cochlear hair cell stereocilia.

The results of the present work then, demonstrate that simple rapid freezing procedures can be applied to preparations of isolated cochlear hair cells enabling ultrastructural examination of unfixed cells and the application of deep-etching. The results also show that hair cell isolation procedures do not have significant effects on cell structure but prolonged incubation in culture medium can induce alterations to the membrane of lateral cisternae which may be the consequence of maintaining cells at room temperature. Additional work is necessary to substantiate this conclusion, but perhaps studies of the activities of isolated outer hair cells should be performed at $37^{\circ} \mathrm{C}$ rather than at room temperature. Further work is also necessary to discover whether the absence of certain extracellular components, particularly tip-links, from the surfaces of the stereocilia of the hair cells examined in this study is a reflection of the actual situation in vivo or is either a consequence of the exposure of stereocilia to an inappropriate environment or an artefact of the preparation procedure. 


\section{Acknowledgements}

We are extremely grateful to Dr M. J. Costello for most generously given advice. The work was supported in part by a NATO Collaborative Research Award. We also thank the Wellcome Trust, Hearing Research

\section{References}

ARIMA, T., UEMARA, T. \& YAMAMOTO, T. (1986) Cytoskeletal organisation in the supporting cell of the guinea pig organ of Corti. Hearing Research 24, 169-75.

ARIMA, T., UEMARA, T. \& YAMAMOTO, T. (1987) Threedimensional visualisations of the inner ear hair cell of the guinea pig. A rapid-freeze, deep-etch study of filamentous and membranous organelles. Hearing Research 25, $61-8$.

ASHMORE, J. (1987) A fast motile response in guinea pig outer hair cells: the cellular basis of the cochlear amplifier. Journal of Physiology 388, 323-47.

BILLET, T. E., THORNE, P. R. \& GAVIN, J. B. (1989) The nature and progression of injury in the organ of Corti during ischaemia. Hearing Research 41, 189-98.

BROWNELL, W. E., BADER, C. R., BERTRAND, D. \& RIBEAUPIERRE, Y. de (1984) Evoked mechanical responses of isolated cochlear outer hair cells. Science 227, 194-6.

Costello, M. J., fetter, R. \& Hochli, M. (1982) Simple procedures for evaluating the cryofixation of biological samples. Journal of Microscopy 125, 125-36.

COSTELlo, M. J., FETTER, R. \& CORLESS, J. M. (1984) Optimum conditions for the plunge freezing of sandwiched samples. In Science of Biological Specimen Preparation (edited by REVEL, J.-P., BARNARD, T. \& HAGGIS, G. H) pp. 105-15. Chicago: SEM Inc.

DAvies, S. \& FORGE, A. (1987) Preparation of the mammalian organ of Corti for scanning electron microscopy. Journal of Microscopy 147, 89-101.

DE LEEUW, F. E., CHEN, H.-C., COLENBRANDER, B. \& VERKLEIJ, A. J. (1990) Cold-induced ultrastructural changes in bull and boar sperm plasma membranes. Cryobiology 27, 171-83.

DULON, D., ARAN, J.-M. \& SCHACHT, J. (1987) Osmotically induced motility of outer hair cells: implications for Meniere's disease. Archives of Oto-Rhino-Laryngology 244, $104-7$.

DULON, D., ZAJIC, G. \& SCHACHT, J. (1988) K+ depolarisation induces motility in outer hair cells by an osmotic mechanism. Hearing Research 32, 123-30.

DULON, D., ZAJIC, G. \& SCHACHT, J. (1990) Increasing intracellular free calcium induces circumferential contractions in isolated cochlear outer hair cells. Journal of Neuroscience 10, 1388-97.

EVANS, B. N. (1990) Fatal contractions: ultrastructural and electromechanical changes in outer hair cells following transmembraneous electrical stimulation. Hearing Research 45, 265-82.

FEtTER, R. \& COSTELlo, M. J. (1986) A procedure for obtaining complementary replicas of ultra-rapidly frozen sandwiched samples. Journal of Microscopy 141, 277-90.

FLOCK, A. \& CHEUNG, H. C. (1977) Actin filaments in
Trust, the Special Trustees of The RNTNE Hospital and the Smithkline (1982) Foundation for equipment grants.

sensory hairs of inner ear receptor cells. Journal of Cell Biology 75, 339-43.

FLOCK, A., FLOCK, B. \& ULFENDAHL, M. (1986) Mechanisms of movement in outer hair cells and a possible structural basis. Archives of Oto-Rhino-Laryngology 243, 83-96.

FORGE, A. (1986) The morphology of the normal and pathological cell membrane and junctional complexes of the cochlea. In Basic and Applied Aspects of Noise-Induced Hearing Loss (edited by SALVI, R. J., HENDERSON, D., HAMERNIK, R. J. \& COLLETTI, V.) Pp. 55-68. New York: Plenum Publishing Corporation.

FORGE, A. (1987) Specialisations of the lateral membrane of inner hair cells. Hearing Research 31, 99-110.

FORGE, A. (1989) The lateral walls of inner and outer hair cells. In Cochlear Mechanisms (edited by WILSON, J. P. \& KEMP, D. T.) pp. 29-35. New York: Plenum Publishing Corporation.

FORGE, A., DAVIES, S. \& ZAJIC, G. (1988) Characteristics of the membrane of the stereocilia and cell apex in cochlear hair cells. Journal of Neurocytology 17, 325-34.

FURNESS, D. N. \& HACKNEY, C. M. (1985) Cross-links between stereocilia in the guinea pig cochlea. Hearing Research 18, 177-88.

FURNESS, D. N., RICHARDSON, G. P. \& RUSSELL, I. J. (1989) Stereociliary bundle morphology in organotypic cultures of the mouse cochlea. Hearing Research 38, 95-110.

GILKEY, J. C. \& STAEHELIN, L. A. (1986) Advances in ultrarapid freezing for the preservation of cellular ultrastructure. Journal of Electron Microscopy Technique 3, 177210.

HAGGIS, G. H. (1985) Towards more precise definition of conditions for satisfactory deep etching. Journal of Microscopy 139, 49-55.

HEUSER, J. E. \& SALPETER, S. R. (1979) Organisation of acetylcholine receptors in quick-frozen, deep-etched, and rotary-replicated Torpedo postsynaptic membrane. Journal of Cell Biology 82, 150-73.

HEUSER, I. E., REESE, T. S., DENNIS, M. J., JAN, Y., JAN, L. \& EVANS, L. (1979) Synaptic vesicle exocytosis captured by quick freezing and correlated with quantal transmitter release. Journal of Cell Biology 81, 275-300.

HIROKAWA, N. \& TILNEY, L. G. (1982) Interactions between actin filaments and between actin filaments and membranes in quick-frozen and deeply etched hair cells of the chick ear. Journal of Cell Biology 95, 249-61.

HOLley, M. C. (1988) Purification of mammalian cochlear hair cells using small volume Percoll density gradients. Journal of Neuroscience Methods 27, 219-24.

HUDSPETH, A. J. (1989) How the ear's works work. Nature $341,397-404$.

KEMP, D. T. (1978) Stimulated acoustic emission from within 
the human auditory system. Journal of the Acoustical Society of America 64, 1386-91.

MCDOWELL, B., DAVIES, S. \& FORGE, A. (1989) The effect of gentamicin-induced hair cell loss on the tight junctions of the reticular lamina. Hearing Research 40, 221-32.

MENCO, B.Ph.M. (1986) A survey of ultra-rapid cryofixation methods with particular emphasis on applications to freeze-fracturing, freeze-etching, and freeze-substitution. Journal of Electron Microscopy Technique 4, 177-240.

MILLER, K. R., PRESCOTT, C. S., JACOBS, T. L. \& LASSIGNAL, N. L. (1983) Artefacts associated with quick-freezing and freeze-drying. Journal of Ultrastructure Research 82, 123-33.

NEWMAN, T. M. \& DUCE, I. R. (1986) Preparation-dependent distribution of intramembrane particles in freeze-fracture replicas of the neuromuscular junction of the locust Schistocerca gregaria. Cell \& Tissue Research 243, 323-7.

OSBORNE, M. P. \& COMIS, S. D. (1990) High resolution scanning electron microscopy of stereocilia in the cochlea of normal, postmortem, and drug-treated guinea pigs. Journal of Electron Microscopy Technique 15, 254-60.

PHILliPS, T. E. \& BOYNE, A. F. (1984) Liquid nitrogen-based quick freezing: experiences with bounce-free delivery of cholinergic nerve terminals to a metal surface. Journal of Electron Microscopy Technique 1, 9-29.

PICKLES, J. O., COMIS, S. D. \& OSBORNE, M. P. (1984)
Cross-links between stereocilia in the guinea pig organ of Corti, and their possible relation to sensory transduction. Hearing Research 15, 103-12.

PINTO DA SILVA, P. (1972) Translational mobility of the membrane intercalated particles of human erythrocyte ghosts, $\mathrm{pH}$ dependent, reversible aggregation. Journal of Cell Biology 53, 777-87.

RUSSELL, I. J., RICHARDSON, G. P. \& CODY, A. R. (1986) Mechanosensitivity of mammalian auditory hair cells in vitro. Nature 321, 517-19.

SANTI, P. A. \& ANDERSON, C. B. (1987) A newly identified cell coat on cochlear hair cells. Hearing Research 27, 47-66.

SEVERS, N. \& ROBENEK, H. (1983) Detection of microdomains in biomembranes. An appraisal of recent developments in freeze-fracture cytochemistry. Biochemica et Biophysica Acta 737, 373-408.

SHIRANE, M. \& HARRISON, R. V. (1987) The effects of deferoxamine mesylate and hypoxia on the cochlea. Acta Otolarygologica 104, 99-107.

ZAJIC, G, \& SCHACHT, I. (1987) Comparison of isolated outer hair cells from five mammalian species. Hearing Research 26, 249-56.

ZENNER, H. P., ZIMMERMANN, U. \& SCHMITT, U. (1985) Reversible contraction of isolated cochlear hair cells. Hearing Research 18, 127-33. 